\title{
Fizyolojik Pes Planus Görülen Çocuklarda Alt Ekstremite Biyomekaniksel Özellikleri ile Sağlıkla İlgili Yaşam Kalitesi ile Arasındaki İlişkinin İncelenmesi - Pilot Çalışma
}

\author{
Şulenur YILDIZ 國, Sedef ŞAHIN [i] $^{2}$, Nilgün BEK [i] $^{3}$
}

\begin{abstract}
ÖZ
Amaç: Bu pilot çalışmanın amacı, fizyolojik pes planus görülen çocuklarda, sağlıkla ilgili yaşam kalitesi ile alt ekstremitenin biyomekaniksel karakteristikleri arasında ilişkinin araştırılmasıydı.

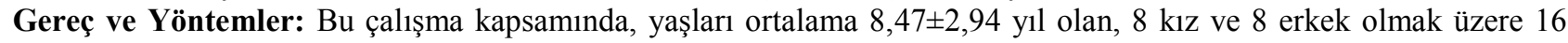
fizyolojik pes planusu olan çocuğun 32 alt ekstremitesi incelendi. Olguların alt ekstremitelerine ait biyomekaniksel özelliklerinin ortaya konabilmesi amacıyla, metatarsal esneklik (ME), ağırlıklı topuk-bacak açısı (TBA-WB), navikular düşme testi (NDT), Ayak Postür İndeksi (API), ayak bileği plantar fleksor kas kısalığı, popliteal açı (PA) ve Beighton Skoru (BS) değerlendirildi. Sağlıkla ilgili yaşam kalitesinin değerlendirmesinde, Çocuklar için Yaşam Kalitesi Ölçeği ÇIYYKÖ-Çocuk Formu kullanıldı. Çalışma kapsamında ayrıca, ebeveynlerin çocuklarının sağlıkla ilgili yaşam kalitesine bakış açısını değerlendiren ÇiYKÖ-Ebeveyn Formu uygulandı.

Bulgular: Olguların ÇiYKÖ-Çocuk formunun fiziksel, sosyal, emosyonel, okul, psikososyal sağlık özet skoru ve toplam skorlar ile ME, TBA-WB, API, plantar fleksor kas kısalığı, PA ve BS verileri arasında anlamlı ilişki bulunmadı ( $>>0,05)$. ÇiYKÖ-Ebeveyn formuna göre ise, fiziksel skor ile sağ alt ekstremite PA $(r=0,535 ; p=0,048)$, sosyal skoru ile sol PA $(r=0,537 ; p=0,048)$ ve ÇiYKÖ toplam skoru ile sol PA verileri arasında pozitif ve anlamlı ilişki bulundu $(r=$ $0,702 ; \mathrm{p}=0,005)$.

Sonuç: Fizyolojik pes planus görülen çocukların, sağlıkla ilgili yaşam kalitesi ile alt ekstremitenin biyomekaniksel karakteristikleri arasındaki ilişkiyi araştırdığımız pilot çalışmamızın sonuçlarına göre, değerlendirilen parametreler açısından klinik öneme sahip herhangi bir ilişki bulunmadı. Daha fazla sayıda ve farklı şiddetlerdeki patolojilere göre gruplanmış olgu sayısının dahil edildiği, görülen patolojilerin bireyin yaşam kalitesine etkisini kendi algısı ve ebeveyn algının karşılaştıııldığı çalışmalara gereksinim duyulmaktadır.
\end{abstract}

Anahtar Kelimeler: Ayak; çocuk; düz taban; yaşam kalitesi.

\section{The Relationship Between Lower Extremity Biomechanical Features and Health-Related Quality of Life in Children with Physiological Pes Planus - A Pilot Study}

\begin{abstract}
Aim: The aim of this study was to investigate the relationship between the health related quality of life and biomechanical characteristics of the lower extremity in children with physiological pes planus.

Material and Methods: In this study, 32 lower extremities of 16 children with physiological pes planus (8 girls and 8 boys) with an average age of $8.47 \pm 2.94$ years were examined. Metatarsal flexibility (ME), weighted heel-leg angle (TBA-WB), navicular drop test (NDT), Foot Posture Index (FPI), ankle plantar flexor muscle shortness, popliteal angle (PA) and Beighton Score (BS) were used to evaluate the anthropometric properties of the lower extremities. The Pediatric Quality of Life Inventory (PedsQL)-Child Form was used to evaluate health-related quality of life. The PedsQL-Parent Form, which evaluates the parents' perspective on their children's health-related quality of life, was also applied.
\end{abstract}

Results: There was no significant relationship between the physical, social, emotional, school, psychosocial health summarv score and total scores of the PedsOL-Child form of the cases and the data of ME. TBA-WB. FPI. plantar

1 Hacettepe Üniversitesi, Fizik Tedavi ve Rehabilitasyon Fakültesi, Ankara, Türkiye

2 Hacettepe Üniversitesi, Sağlık Bilimleri Fakültesi, Ergoterapi Bölümü, Ankara, Türkiye

3 Lokman Hekim Üniversitesi, Sağlık Bilimleri Fakültesi, Fizyoterapi ve Rehabliitasyon Bölümü, Ankara, Türkiye 
muscle shortness, PA, and BS ( $p>0.05)$. According to the PedsQL-Parent form, there was a positive and significant relationship between physical score and right lower extremity PA( $\mathrm{r}=0.535 ; \mathrm{p}=0.048)$, social score and left PA $(\mathrm{r}=0.537 ; \mathrm{p}=0.048)$, and PedsQL total score and left $\mathrm{PA}(\mathrm{r}=0.702 ; \mathrm{p}=0.005)$.

Conclusion: According to our study, the relationship between the health-related quality of life and the biomechanical characteristics of the lower extremity in children with physiological pes planus did not indicate any clinical significance in terms of evaluated parameters. There is a need for studies with a larger number of cases grouped according to pathologies of different severity and the effects of pathologies seen on the individual's quality of life, and comparison of child's own and parental perception.

Keywords: Foot; child; pes planus; quality of life.

\section{GíRIS}

Pes planus, ayağı destekleyen en önemli ark olan medial longitudinal arkın yüksekliğini kaybetmesi, arka ayağın valgusu ve orta ayağın arka ayağa göre abduksiyonunu içerebilen ve çocukluk çağından itibaren yaygın olarak görülen bir ayak problemidir (1). Her yaş grubunda rastlanmakla birlikte pediatrik grupta yürümeye yeni başlayan bebekler ve okul çağı çocuklarında sık görülürken çoğunlukla ayak gelişiminin tamamlanmasıyla ergenlikle birlikte azalır ya da ortadan kalkar $(1,2)$. Kas kısalıkları, obezite ile birlikte artmış eklem laksitesi, W şeklinde oturma, erkek cinsiyet ve genetik alt yap1 pediatrik popülasyonda pes planus görülme sıklığını ve şiddetini arttırabilen faktörler arasındadır (2-4).

Ekstremiteye ağırlık verilmediği veya alt ekstremitenin açık kinetik zincir pozisyonlarında belirgin olan medial longitudinal arkın, vücut ağırlığıyla birlikte ortadan kaybolması esnek veya fizyolojik pes planus olarak adlandırılmaktadır $(3,5)$. Büyüme sürecinde fizyolojik gelişimin bir parçası olan bu durum, çoğunlukla asemptomatik seyreder. Fizyolojik pes planusta, ayak başparmağı ekstansiyona alındığında çıkrık mekanizması devreye girerek medial longitudinal arkın yüksekliğini arttırırken, ağırlık vermeden bağımsız olarak arkın düşük olduğu ve yapısal kemik deformitelerinin de eşlik edebildiği ark yükselmesinin gözlenmediği duruma rijit pes planus denir (3). Literatürde üç ve altı yaş aralığındaki çocuklarda fizyolojik pes planusun \%44 oranında görüldüğü belirtilirken, rijit pes planusun görülme oranının \%1'in altında olduğu ifade edilmektedir (6). Öte yandan fizyolojik pes planusun, $\% 4-23$ oranında yetişkin döneme de taşındığı farklı çalışmalarda gösterilmekte ve fizyolojik pes planusu olan bazı çocuklarda ilerleyen zamanlarda semptom görülürken, diğerlerinde görülmemesinin nedeni ile ilgili net bir bilgiye ulaşılmamaktadır (7-9).

Literatürde pes planusun belirlenebilmesine yönelik altın standart bir yöntem bulunmamaktadır. Radyografik görüntüleme teknikleri bile, arkın yüksekliğini belirlemek için kullanılabilecek net bir yöntem olarak görülmemekte, çekim pozisyonu ve tekniği gibi etkenlerin sonucu değiştirmesi yanında pediatrik grupta $X$ 1şınlarına maruziyet nedeniyle tercih edilmemektedir (3). Ayak postürüne odaklanmış gözlemsel değerlendirmeler ve ayak izi yöntemleri klinikte daha sık tercih edilen yöntemler arasında yer almaktadır (10). Navikular düşme testi, medial longitudinal arkın esnekliği ile ilgili fikir veren klinikte kolay uygulanabilen, uygulayıcılar arası ve uygulamalar arası güvenirliği yüksek ve çalışmalarda da sıklıkla kullanılan geçerli bir yöntemdir (10).

Farklı şekillerde patomekanik değişiklikler görülen alt ekstremite ve ayağın, yaşam kalitesi üzerine etkilerini değerlendiren çalışmaların literatürde sınırlı sayıda olduğu görülmektedir (11-14). Normal gelişim gösteren ayağa sahip çocuklarla fizyolojik pes planusu olan çocukların yaşam kalitelerinin karşılaştırıldığı bir çalışmada, en çok fiziksel parametrelerde olmak üzere pes planusu olan grupta yaşam kalitesinin daha olumsuz etkilendiği belirtilmiştir (11). Okul çağı çocuklarında yapılan bir diğer çalışmada ise ayaklar pes kavus ve pes planus olarak sınıflandırılarak karşılaştırılmış ve yaşam kaliteleri açısından gruplar arasında belirgin bir fark gösterilmemiştir (12). Üniversite öğrencileri ile yapılan bir çalışmada, pes planusun yaşam kalitesini olumsuz etkilediği belirtilmiştir (13). Yetişkin sağlıklı grupta yapılan kesitsel bir çalışmada ise, yaşam kalitesi ve alt parametreleri açısından (genel değerlendirme ve ayağa özel yaşam kalitesi değerlendirmesi) pes planus, pes kavus ve normal arka sahip bireyler arasında fark görülmediği rapor edilmiştir (14). Literatürde fizyolojik pes planusa sahip ve vücut kütle indeksleri normal sınırlarda olan çocuklarda yürüyüş ile yaşam kalitesi arasındaki ilişkisi incelenmesine rağmen alt ekstremitenin antropometrik ve biyomekanik özelliklerinin yaşam kalitesi ile ilişkilerine ait literatürde çalışmaya rastlanmamıştır (11).

Fizyolojik pes planus yaklaşımlarıyla ilgili literatürde farklı görüşler bulunmakla birlikte; uzun vadede eklem hasarı ile fonksiyonel problemlere neden olabilme ihtimali nedeniyle düzenli takibin önemi vurgulanmaktadir (15). $\mathrm{Bu}$ nedenle bu grupta alt ekstremitenin biyomekaniksel özelliklerinin belirlemesi ile takibi kadar sağlıkla ilgili yaşam kalitesinin takibinin de önemli olduğu ve prognozun gidişatı hakkında fikir verebileceği düşünülmektedir. $\mathrm{Bu}$ bilgiler 1şı̆̆ıında planlanan pilot çalışmamızda, fizyolojik pes planus görülen pediatrik bireylerde, sağlıkla ilgili yaşam kalitesi parametreleri ile alt ekstremite biyomekaniksel karakteristikleri arasında herhangi bir ilişki olup olmadığını yönünde yol gösterici olması amaçlanmıştır.

\section{GEREÇ VE YÖNTEMLER \\ Olgular}

Çalışma kapsamında 16 çocuk değerlendirildi. Çalışma öncesi, Hacettepe Üniversitesi, Girişimsel Olmayan Klinik Araştırmalar Etik Kurulu'ndan GO 19/980 ve 15.10.2019 onay tarihli sayılı karar ile etik kurul onayı alınarak, bütün olgular çalışma hakkında bilgilendirildi ve olguların ile ebeveynlerinden bilgilendirilmiş olurları alındı. Çalışma sürecinde araştırma ve yayın etiği prensipleri dikkate alınarak Helsinki Deklerasyonu Prensipleri'ne uyuldu.

Çalışmaya 5-18 yaş aralığında, Navikular Düşme Testi (NDT) miktarı $10 \mathrm{~mm}$ 'den büyük olan, asemptomatik, yürüyüşü etkileyecek nörolojik bir tanısı olmayan, bağımsız yürüme yeteneğine sahip, çalışmaya katılmaya kendisi ve ebeveynleri gönüllü olan bireyler dahil edildi. 
Sistemik bir hastalığı hikayesi, alt ekstremite cerrahisi geçmişi olan ve çalışmaya katılmaya kendi ve/veya ailesi gönüllü olmayan bireyler çalışmaya dahil edilmedi.

\section{Yöntem}

Çalışmaya katılan bireylerin yaş, vücut ağırlığı, boy uzunluğu kaydedildi ve vücut kütle indeksi hesaplandi. Alt ekstremite dominantlığını belirlemek için bireylerden ayakta duruş pozisyonunda ayaklar ortasına yerleştirilmiş olan topa vurmaları istendi ve topa vuran taraftaki ekstremite dominant taraf olarak kabul edildi (16). Bütün değerlendirmeler tüm olgulara bilateral olarak uygulandı.
1. Bağımsız
Değişkenler
(Biyomekaniksel

Karakteristikler)

Metatarsal Esneklik (ME): Ön ayak yapılarının vücut ağırlığına olan cevabının değerlendirmesi için kaliper yardımı ile ağırlıklı ve ağırlıksız pozisyonlarda ölçülen metatarsal genişlik değerleri santimetre cinsinden kaydedildi. Ağırlıklı pozisyonda elde edilen metatarsal genişlik değerinden ağırlıksız pozisyonda elde edilen metatarsal genişlik değeri çıkarılarak elde edilen fark değeri ME olarak hesaplandı ve santimetre cinsinden kaydedildi (17).

Ăğırlıklı Topuk-Bacak Açısı (TBA-WB): Kalkaneus ve subtalar eklemin bacağa göre pozisyonunu değerlendirmek amacıyla kullanılan TBA-WB ölçümü, ayakta durma pozisyonunda, bacak uzun ekseni ile kalkaneus orta noktasındaki açının gonyometre ile ölçülerek derece cinsinden kaydedilmesiyle elde edildi (18). Nötrale göre varusta ölçülen değerler negatif olarak kaydedilirken, valgustaki değerler pozitif olarak not edildi. Beş dereceden fazla valgusun görülmesi, normal ayak basıncının bozulması sonucunda pes planusa gidiş olarak yorumlandi (19).

Kas Kısalıkları: Ayak bileği plantar fleksor ve diz fleksor kaslarının kısalıkları değerlendirildi. Ayak bileği plantar fleksor kas kısalığı, sırtüstü yatış pozisyonunda dizler ekstansiyonda iken gonyometre ile ölçülürken, diz fleksor kaslarının kısalığını değerlendirmek için kullanılan popliteal açı (PA) ölçümünde ise sırt üstü yatış pozisyonunda kalça eklemi 90 derece fleksiyonda pozisyonlanırken diz eklemindeki maksimum ekstansiyon derecesi kaydedildi $(20,21)$.

Ayak Postürü: Katılımcıların ayak postürlerinin değerlendirilmesinde klinikte pediatrik grup için de geçerli ve güvenilir olarak kullanılan bir değerlendirme yöntemi olan Ayak Postür İndeksi (APİ) kullanıldı (22). Altı maddeden oluşan bu değerlendirme ölçeğinde, talus başı palpasyonu, kalkaneus pozisyonu, lateral malleol altı ve üstündeki eğim, talonavikular eklem pozisyonu, medial longitudinal arkın yapısı ve ayak ön kısmının arka kısmına göre pozisyonun değerlendirilmesi sonucunda 12 ile +12 arasında alınan skorlara göre ayak postürü nötral, pronasyon ya da supinasyonda olarak tanımlandı.

Navikular Düşme Testi (NDT): Talar pronasyonu, talonavikülar eklemin ve navikulanın vertikal plandaki pozisyonu ve medial longitudinal arkın ağırlık değişimlerine karşı fleksibilitesini değerlendirmek amacıyla NDT kullanıldı. Navikular tüberkülün ağırlıksız ve ağırlıklı pozisyonda yerden yüksekliğinin işaretlendiği kart üzerindeki fark cetvel ile ölçülerek iki değer arasındaki fark alındı. Bu farkın 6-9 mm arasında olması ayak arkının normal olduğunu işaret ederken, $10 \mathrm{~mm}$ üzeri değerlerde arkın düşük olduğu şeklinde yorumlandı ve bu değerlendirme dahil edilme kriterleri kapsamında kullanıld1 (23).

Eklem Laksitesi: Olgularımızda genel eklem hipermobilitesini değerlendirmek için Beighton Skoru kullanıld1. Beighton Skoru (BS), 5.metakarpal eklemin ekstansiyonu, başparmağın ön kol iç yüzüne değebilmesi, dirseğin 10 dereceden fazla hiperekstansiyonu, dizin 10 dereceden fazla hiperekstansiyonu, dizler hiperekstansiyonda iken el ayasının yere değmesi gibi beş manevranın uygulanması ile puanlanan ve her pozitif madde için 1 puanın alındığ 1 bir ölçektir. $\mathrm{Bu}$ manevralardan dördü pozitifse hipermobilite varlığ düşünülmektedir. İlk dört madde tüm ekstremitelerde simetrik olarak değerlendirilirken, pozitif maddeler için 1 puan alınmaktadır. Son madde ve yapılabilen her hareket için bir puan bir kez değerlendirilir ve en yüksek skor 9 puandır (24). Toplamda dört puan ve üstü alan bireylerde genel hipermobilite varlığ 1 ifade edilmektedir.

2. Bağımlı Değişkenler (Yaşam Kalitesi Değerlendirmesi)

Sağlıkla İlişkili Yaşam Kalitesi: Çocukların sağlıkla ilişkili yaşam kalitesinin değerlendirilmesinde 2-18 yaşlar (2-4 yaş, 5-7 yaş, 8-12 yaş ve 13-18 yaş grupları) arasında kullanım seçenekleri olan ve aynı zamanda ebeveynlerin bakış açısından çocuğun yaşam kalitesini değerlendiren ebeveyn formu içeren, pediatrik grupta genel sağlık durumunu değerlendirmek için sıklıkla tercih edilen Çocuklar için Yaşam Kalitesi Ölçeği formları kullanıldı. Olgularımıza ÇİYKÖ-Çocuk Formu ve olgularımızın ebeveynlerine de ÇİYKÖ-Ebeveyn Formu uygulandı ve öncesinde anket kullanım izni alındı (25). Fiziksel, emosyonel, sosyal ve okul alt başlıklarını içeren toplam 23 sorudan oluşan ve 0-100 puan arasında skorlanan bu ölçeklerde, yüksek skorlar daha iyi sağlıkla ilgili yaşam kalitesini işaret etmektedir. Emosyonel fonksiyon, sosyal fonksiyon ve okul fonksiyonu ile ilgili alt başlıklar toplanarak psikososyal sağlık özet skoru elde edilirken, fiziksel fonksiyon alt başlığı ile fiziksel sağlık özet skoru elde edilmektedir. Cevap verilen tüm soruların toplamının soru sayısına bölünmesi ile de toplam skora ulaşılmaktadır (25). Anketin Türkçe geçerlilik güvenirlik çalışması bulunmaktadır $(26,27)$.

\section{İstatistiksel Analiz}

Çalışma kapsamında elde edilen verilerin değerlendirilmesi için SPSS yazılımının 20.0 versiyonu (SPSS Inc., Chicago, ABD) kullanıld1. Elde edilen veriler, medyan ve çeyrekler arası aralık (IQR) olarak ifade edildi. Shapiro Wilk testi kullanılarak verilerin normal dağılıma uygun olmadığı belirlendi ve bu nedenle veriler arasındaki ilişkinin belirlenmesinde Spearman's rho korelasyon analizi kullanıldı. İstatistiksel anlamlılık derecesi $\mathrm{p}<0,05$ olarak kabul edildi.

\section{BULGULAR}

Bu çalışma kapsamında yaşları ortalama 8,47 $\pm 2,94$ yıl olan ve fizyolojik pes planus tanısı alan 8'i kız ve 8'i erkek olmak üzere 16 çocuğun 32 alt ekstremiteleri incelendi. Olgulara ait demografik veriler Tablo 1'de verilmiştir. Olguların 13'ünün sağ alt ekstremitesi dominantken, geri kalan 3 ünün sol alt ekstremitesi dominant olduğu belirlendi. 
Tablo 1. Olgularımıza ait demografik bilgiler

\begin{tabular}{|l|c|c|}
\hline & Medyan & IQR \\
\hline Yaş (yıl) & 9,50 & 4,75 \\
\hline $\begin{array}{l}\text { Boy uzunluğu } \\
(\mathbf{m})\end{array}$ & 1,22 & 0,11 \\
\hline $\begin{array}{l}\text { Vücut ağırlı̆̆ı } \\
\text { (kg) }\end{array}$ & 31,50 & 3,50 \\
\hline VKİ (kg/m²) & 20,71 & 5,70 \\
\hline $\begin{array}{l}\text { Cinsiyet } \\
\text { Kadın / Erkek } \\
\text { n (\%) }\end{array}$ & $\begin{array}{c}\mathrm{n}(\%) \\
8(50) / 8(50)\end{array}$ \\
\hline
\end{tabular}

* VKI: Vücut kitle indeksi; IQR: Çeyrekler arası aralık

Olgularımızdan elde edilen alt ekstremitenin biyomekaniksel karakteristiklerine ait ölçümlerin ve sağlıkla ilişkili yaşam kalitesi değerlendirme sonuçlarının aritmetik ortalama ve standart sapma değerleri Tablo 2'de sunulmuştur.

Tablo 2. Değerlendirme parametrelerine göre tanımlayıcı istatistiksel değerlendirme verileri

\begin{tabular}{|c|c|c|c|c|}
\hline & Medyan & IQR \\
\hline \multirow{2}{*}{\multicolumn{2}{|c|}{ ME (cm) }} & $\mathbf{R}$ & 0,40 & 0,45 \\
\hline & & $\mathbf{L}$ & 0,40 & 0,45 \\
\hline \multirow{2}{*}{\multicolumn{2}{|c|}{ TBA-WB (derece) }} & $\mathbf{R}$ & 7,00 & 6,75 \\
\hline & & $\mathbf{L}$ & 6,00 & 6,50 \\
\hline \multirow{2}{*}{\multicolumn{2}{|c|}{ APİ (-12-+12 puan) }} & $\mathbf{R}$ & 5,00 & 8,00 \\
\hline & & $\mathbf{L}$ & 7,00 & 6,50 \\
\hline \multirow{2}{*}{\multicolumn{2}{|c|}{$\begin{array}{l}\text { Plantar fleksor kas } \\
\text { kısalığı (derece) }\end{array}$}} & $\mathbf{R}$ & 4,00 & 18,50 \\
\hline & & $\mathbf{L}$ & 5,00 & 18,50 \\
\hline \multirow{2}{*}{\multicolumn{2}{|c|}{ PA (derece) }} & $\mathbf{R}$ & 35 & 21 \\
\hline & & $\mathbf{L}$ & 40 & 25,50 \\
\hline \multirow{2}{*}{\multicolumn{2}{|c|}{ BS (0-5 puan) }} & $\mathbf{R}$ & 3 & 4,00 \\
\hline & & $\mathbf{L}$ & 2 & 4,00 \\
\hline \multirow{12}{*}{$\begin{array}{l}\text { ÇİYKÖ } \\
\text { (0-100) }\end{array}$} & & Fiziksel & 85,70 & 31,25 \\
\hline & & Emosyonel & 60,00 & 40,00 \\
\hline & Çocuk & Sosyal & 90,00 & 30,00 \\
\hline & formu & Okul & 70,00 & 40,00 \\
\hline & & PSÖS & 220,00 & 110,00 \\
\hline & & Toplam & 74,68 & 34,37 \\
\hline & \multirow{6}{*}{$\begin{array}{l}\text { Ebeveyn } \\
\text { formu }\end{array}$} & Fiziksel & 43,75 & 43,76 \\
\hline & & Emosyonel & 70,00 & 25,00 \\
\hline & & Sosyal & 70,00 & 21,25 \\
\hline & & Okul & 60,00 & 35,00 \\
\hline & & PSÖS & 201,25 & 70,00 \\
\hline & & Toplam & 64,68 & 23,91 \\
\hline
\end{tabular}

ME: Metatarsal Esneklik; TBA-WB: Ağırlıklı Topuk Bacak Açısı; APİ: Ayak Postur İndeksi; PA: Patellar Açı; BS: Beighton Skoru; R: Sağ; L: Sol; ÇiYKÖ: Çocuklar İçin Yaşam Kalitesi Ölçeği; PSÖS: Psikososyal Sağlık Özet Skoru; IQR: Çeyrekler arası aralık.

Alt ekstremite antropometrik özelliklerini ortaya koymak amacıyla bilateral olarak yapılan ME ölçümü ve TBAWB, plantar fleksor kas kısalığı ve PA ölçümlerine ilişkin sonuçlarımız Tablo 2'de özetlenmektedir. Verilerimize göre olgularımızda plantar fleksor ve diz fleksor kaslarında kısalık tespit edilmemiştir. Ağırlıklı olarak yapılan TBA-WB ölçümü sonucunda bireylerin arka ayak pozisyonlarında hafif şiddette valgus olduğu saptanmıştır. $\mathrm{Bu}$ bulguları destekler nitelikte olmak üzere, ayak postürünün incelenmesinde kullanılan APİ sonuçlarına göre, olgularımızın sağ ve sol ayaklarının her ikisinin de 6 ve üzeri puan alarak pronasyonda olduğu saptanmıştır.
BS skorunun ise, her iki ekstremite için de normal sınırlarda olduğu belirlenmiştir (Tablo 2).

ÇIYYKÖ-Çocuk Formu değerlendirmeleri sonucunda en yüksek puanın sosyal parametrede alındığı ve en düşük puanın emosyonel parametreye ait olduğu görülmüştür. ÇIYKÖ̈-Ebeveyn Formuna göre ise tüm parametreler çocuklara oranla daha düşükken, en düşük puanın okul parametresinde olduğu görülmüştür (Tablo 2).

Çalışmamızın hipotezi olarak öngörülen, sağlıkla ilgili yaşam kalitesi parametrelerinin, alt ekstremite biyomekaniksel karakteristikleri ile olan ilişkisinin istatistiksel olarak incelenmesine ilişkin verilen Tablo 3 ve Tablo 4'te sunulmuştur.

Olgularımızın sağlıkla ilgili yaşam kalitesi parametrelerinin, alt ekstremite biyomekaniksel karakteristikleri ile olan ilişkisine ilişkin verilere bakıldığında, ÇIYKÖ̈-Çocuk Formunun fiziksel, sosyal, emosyonel, okul ve psikososyal sağlık özet skoru ve toplam skorlar ile ME, TBA-WB, plantar fleksor kas kısalığı, PA, APİ ve BS arasında istatiksel olarak herhangi bir ilişki olmadığı görülmüştür $(p>0,05)$. ÇIYYKÖ-Ebeveyn Formu sonuçlarına göre ise sağ PA ile fiziksel skor $(\mathrm{r}=0,535 ; \mathrm{p}=0,048)$, sol PA ile sosyal skor $(\mathrm{r}=0,537 ; \mathrm{p}=0,048)$ ve sol PA ile toplam skor $(\mathrm{r}=0,702 ; \mathrm{p}$ $=0,005)$ arasında istatistiksel olarak pozitif yönde anlamlı ilişki bulunurken geri kalan parametreler arasında herhangi bir ilişki tespit edilmemiştir $(p<0,05)$.

\section{TARTISMA}

Pediatrik popülasyonda sik görülen ve ailelerin önemsediği bir problem olan fizyolojik pes planusta alt ekstremite biyomekaniksel karakteristikleri ile çocuğun yaşam kalitesi ve çocuğun ebeveyn tarafından algılanan sağlıkla ilişkili yaşam kalitesi parametreleri arasındaki ilişkiyi inceleyen çalışmamız sonucunda, fizyolojik pes planusu olan olgularımızda yaşam kalitesi parametreleri ile alt ekstremitelerin ölçülen biyomekaniksel karakteristikleri arasında anlamlı bir ilișki olmadığ görülmektedir. Pediatrik grupta yürüyüş sırasındaki ayak fonksiyonu ile yaşam kalitesi arasında negatif ilişki bulan çalışmanın aksine çalışmamızda ayağın statik pozisyondaki biyomekaniksel özellikleri ile yaşam kalitesi arasında ilişki saptanmamasının nedeni fizyolojik pes planusun dinamik fonksiyonu daha fazla etkiliyor olması olabilir, olgu sayısı arttırılarak bu sonuç tekrar incelenmelidir (11).

Ön ayağın yüklenmeye cevabını değerlendiren ve özellikle pediatrik bireyler için belirlenmiş sayısal bir norm değeri olmayan metatarsal esneklik ölçümleri sonucunda, sağ ve sol ekstremitelerin benzer cevaplar gösterdiği ancak yaşam kalitesi parametreleriyle ilişkili bulunmadığı görülmüştür. $\mathrm{Bu}$ durum değerlendirme grubumuzun pes planus şiddetleri ileri derece olmayan ve ayakları hafif pronasyon postüründeki çocukları kapsamasıyla açıklanabilir.

Yaşam kalitesi parametreleri ile arka ayak pronasyonunu gösteren TBA-WB değerleri aralarında bir ilişkinin görülmüyor olmasının nedeni, literatürdeki artmış dinamik arka ayak eversiyonu olan olgularda daha fazla etkilenmiş yaşam kalitesi sonuçlarına göre zıtlık içermesinin nedeni ölçümlerin dinamik ve statik özelliklerinden kaynaklanabilir (11). 
Tablo 3. Sağlıkla ilgili yaşam kalitesi çocuk formu parametreleri ile ölçülen alt ekstremite biyomekaniksel karakteristikleri arasındaki ilişki

\begin{tabular}{|c|c|c|c|c|c|c|c|}
\hline & & & & ÇİY & Çocuk & & \\
\hline & & Fiziksel & Emosyonel & Sosyal & Okul & PSÖS & Toplam \\
\hline & $\mathrm{r}$ & $-0,423$ & $-0,210$ & $-0,250$ & $-0,378$ & $-0,460$ & $-0,522$ \\
\hline Yaş & $\mathrm{p}$ & 0,171 & 0,511 & 0,432 & 0,226 & 0,133 & 0,082 \\
\hline & $\mathrm{r}$ & 0,050 & $-0,278$ & 0,191 & 0,107 & 0,059 & 0,093 \\
\hline ME-R & $\mathrm{p}$ & 0,892 & 0,437 & 0,597 & 0,769 & 0,872 & 0,799 \\
\hline & $\mathrm{r}$ & $-0,057$ & $-0,376$ & 0,227 & $-0,035$ & 0,028 & 0,025 \\
\hline ME-L & $\mathrm{p}$ & 0,876 & 0,284 & 0,528 & 0,923 & 0,938 & 0,945 \\
\hline TBA-WB-R & $\mathrm{r}$ & 0,304 & 0,040 & $-0,075$ & 0,090 & $-0,231$ & 0,079 \\
\hline IBA-WB-R & $\mathrm{p}$ & 0,393 & 0,913 & 0,836 & 0,805 & 0,521 & 0,828 \\
\hline & $\mathrm{r}$ & 0,203 & $-0,469$ & $-0,707$ & $-0,166$ & $-0,603$ & $-0,142$ \\
\hline 1ВА-WB-L & $\mathrm{p}$ & 0,574 & 0,172 & 0,293 & 0,646 & 0,065 & 0,696 \\
\hline & $\mathrm{r}$ & $-0,268$ & 0,041 & $-0,215$ & $-0,313$ & $-0,346$ & $-0,297$ \\
\hline PF Kisalik-R & $\mathrm{p}$ & 0,425 & 0,904 & 0,526 & 0,348 & 0,298 & 0,375 \\
\hline & $\mathrm{r}$ & $-0,264$ & $-0,061$ & $-0,274$ & $-0,053$ & $-0,271$ & $-0,280$ \\
\hline PF Kisalik-L & $\mathrm{p}$ & 0,415 & 0,858 & 0,414 & 0,869 & 0,420 & 0,405 \\
\hline & $\mathrm{r}$ & 0,113 & 0,428 & $-0,088$ & 0,046 & 0,144 & $-0,053$ \\
\hline PA-R & $\mathrm{p}$ & 0,727 & 0,165 & 0,785 & 0,886 & 0,654 & 0,871 \\
\hline & $\mathrm{r}$ & 0,044 & 0,435 & $-0,068$ & $-0,053$ & 0,093 & $-0,004$ \\
\hline PA-L & $\mathrm{p}$ & 0,892 & 0,157 & 0,833 & 0,869 & 0,773 & 0,991 \\
\hline & $\mathrm{r}$ & 0,257 & $-0,101$ & $-0,324$ & 0,074 & $-0,134$ & 0,079 \\
\hline API- R & $\mathrm{p}$ & 0,474 & 0,781 & 0,361 & 0,839 & 0,712 & 0,828 \\
\hline & $\mathrm{r}$ & 0,022 & $-0,080$ & $-0,498$ & $-0,037$ & $-0,276$ & $-0,166$ \\
\hline API-L & $\mathrm{p}$ & 0,953 & 0,826 & 0,143 & 0,919 & 0,440 & 0,647 \\
\hline BS-R & $\mathrm{r}$ & 0,416 & 0,009 & 0,338 & 0,389 & 0,364 & 0,483 \\
\hline BS-R & $\mathrm{p}$ & 0,266 & 0,982 & 0,374 & 0,300 & 0,336 & 0,188 \\
\hline BS-L & $\mathrm{r}$ & 0,352 & 0,039 & 0,380 & 0,456 & 0,429 & 0,445 \\
\hline BS-L & $\mathrm{p}$ & 0,353 & 0,920 & 0,303 & 0,217 & 0,249 & 0,231 \\
\hline
\end{tabular}

R: Sağ; L: Sol; ME: Metatarsal Esneklik; TBA-WB: Ağırlıklı Topuk Bacak Açısı; APİ: Ayak Postur İndeksi; PA: Patellar Açı; BS: Beighton skoru; ÇIYKKÖ: Çocuklar İçin Yaşam Kalitesi Ölçeği; PSÖS: Psikososyal Sağlık Özet Skoru; PF: Plantar Fleksor

Tablo 4. Sağlıkla ilgili yaşam kalitesi ebeveyn formu parametreleri ile ölçülen alt ekstremite biyomekaniksel karakteristikleri arasındaki ilișki

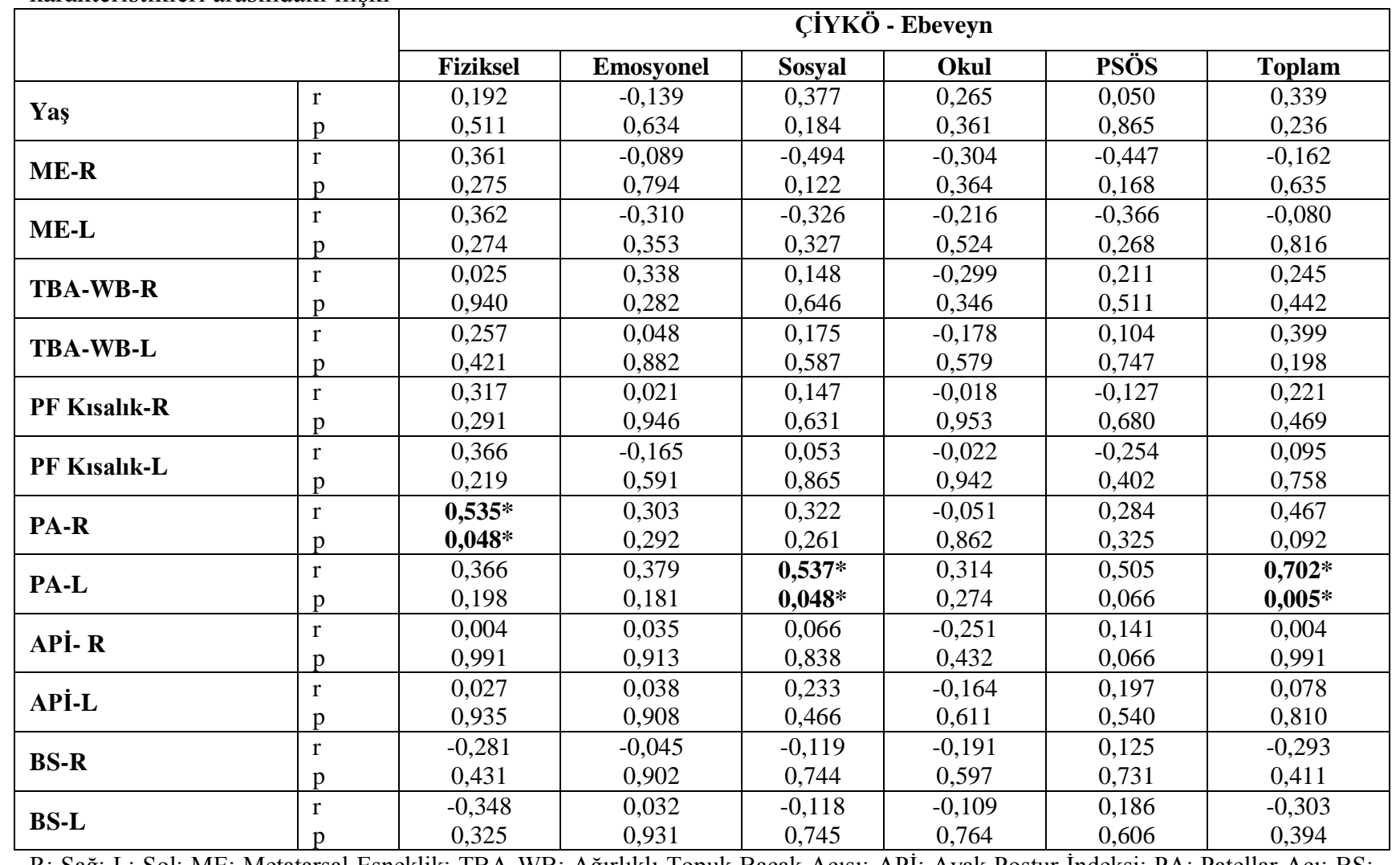

R: Sağ; L: Sol; ME: Metatarsal Esneklik; TBA-WB: Ağırlıklı Topuk Bacak Açısı; APİ: Ayak Postur İndeksi; PA: Patellar Açı; BS: Beighton skoru; ÇiYKÖ: Çocuklar İçin Yaşam Kalitesi Ölçeği; PSÖS: Psikososyal Sağlık Özet Skoru; PF: Plantar Fleksor 
Artmış ve uzamış pronasyonda yürüyüş sırasında ayak olması gerekenden daha fazla ve uzun süre esnek pozisyonda kalarak hem yaralanmalara yatkın hale gelebilirken, plantar basınç değişimleri de görülmekte ve yaşam kalitesini olumsuz etkileyebilmektedir $(11,19)$. Çalışmamızda kullandığımız statik değerlendirmeler, yaşam kalitesi ile ilişkili bulunmamakla birlikte olgu sayısının arttırıldığı ana çalışma sonucunda daha kesin bir kanıya varılabilir.

Plantar fleksor kas kısalığının arka ayaktaki pronasyonu aşırılaştırarak fizyolojik pes planusa ve sonrasında da rijit pes planusa neden olabileceğini öne sunan çalışmalara ek olarak, yürüyüşün ikinci yuvarlanma fazında ayak bileğinin 10 derecelik dorsifleksiyon hareketinin önemli olduğu da bilinmektedir (28). Bu parametrenin çocuğun yaşam kalitesi ve ebeveynlerinin gözünden çocukların yaşam kaliteleri ile ilişkili bulunmamasının nedeninin olgularımızın literatürde 10 dereceden az dorsifleksiyon limitasyonuna sahip olması ve ayak fonksiyonunu olumsuz etkileyecek tanımlanan bir plantar fleksor kas kısalığının olmamasından kaynaklanıyor olabilir $(28,29)$. Literatürde fizyolojik pes planusu olan olgularda, plantar fleksor kas kısalığının eşlik etmesi durumunda bireylerde semptomlar açığa çıkarma ihtimalinin arttığı bilinmektedir (30). Olgularımızda plantar fleksor kas kısalığının gözlenmiyor olması, ayakta fonksiyonunu olumsuz etkilememesi ve yaşam kalitesini olumsuz etkilememesi yönünden literatür ile uyumludur (30).

Literatüre göre, diz fleksor kaslarının kısalığını değerlendirmek amacıyla kullanılan PA değerinin, çocuklarda 50 derecenin altında ölçülmesi normal olarak kabul edilmekte ve üzerindeki değerlerin diz fleksor kas kısalığı olarak kabul edildiği belirtilmektedir (20). Çalışma popülasyonumuzda fleksor kas kısalığı belirlenmemiş ancak, sağ alt ekstremite PA değeri ile ÇIYKÖO-Ebeveyn fiziksel ve sol alt ekstremite PA değeri ile ÇIYYKÖ-Ebeveyn sosyal ve ÇİYKÖ-Ebeveyn toplam skorları arasındaki ilişki istatistiksel olarak anlamlı bulunmuştur. İstatistiksel olarak elde edilen bu sonuçların bu çalışma kapsamında yorumlanması güçtür.

Bilateral olarak elde edilen APİ değerleri artmaya başlayan pronasyon durumunu göstermesine rağmen yaşam kalitesi parametreleri ile herhangi bir ilişkinin olmamasının nedeni, pediatrik grupta bu yaşlarda görülen fizyolojik pes planusun normal fizyolojik gelişiminin bir parçası olması ve olgularımızın ayaklarında yapısal bir sorun olmamasından kaynaklanabilir. Ayaktaki yapıların gelişim aşamasında olduğu bu süreçte arkın tam şeklini alması ve ayağın vücut ağırlığına adapte olması onlu yaşları bulmaktadır (1). Semptom vermeyen fizyolojik pes planusun görüldüğü olgularımızda ayak yapılarındaki yüklenmeye karşı gelişen fizyolojik sınırlardaki bu değişikliklerin fonksiyonu ve dolayısıyla da yaşam kalitesini etkilemediğini düşünebiliriz $(31,32)$.

Genel eklem laksitesi ile birlikte yüksek VKİ'nin eşlik ettiği çocuklarda ayakta pronasyon artışının daha fazla olduğu ve fizyolojik pes planusa eşlik eden olgularda hipermobilitenin semptom açığa çıkarma ihtimalini arttırdığı bilinmektedir (28,30). Genel eklem hipermobilitesini değerlendirmek için kullanılan BS'ye göre de olgularımızda hipermobilite varlığ saptanmamıştır. Olgularımızın vücut kütle indekslerinin normal sinırlarda seyretmesi ve hipermobilite görülmemesi, var olan fizyolojik pes planusun hafif seyretmesine neden olabileceği ve semptom vermeyerek yaşam kalitesini olumsuz etkilemeyeceğini düşündürmektedir $(28,30)$.

Yaşam kalitesi parametreleri kendi içinde değerlendirildiğinde fiziksel sağlıkla ilgili yaşam kalitesinin en yüksek değerde olması, çocukların ağrı ya da fonksiyonel sorunlar gibi semptom veren durumunun olmaması ile ilişkili olabilir. Çocukların yaşam kalitelerine ebeveynlerinin bakış açısı incelendiğinde ise tüm parametrelerin çocukların kendi raporlarına göre daha düşük olması, literatüre benzerlik göstermekte ve ebeveynlerin çocuklara oranla durumu daha olumsuz görmeye yatkın oldukları bulgusunu desteklemektedir (9).

\section{SONUÇ}

Çalışma kapsamında değerlendirilen çocukların uzun süreli takipleri ile yaşam kalitesinin ayak biyomekaniksel özellikleri arasındaki zamana bağlı ilişkilerinin incelenmesine ihtiyaç vardır. Ön çalışma kapsamında yapılan bu çalışmanın olgu sayılarının arttırılması gerekmektedir.

Sonuç olarak; pilot çalışmamızdan elde edilen veriler ışığında, fizyolojik pes planusu olan çocukların ve ebeveynlerinin gözünden yaşam kalitelerinin çocuğun alt ekstremite biyomekaniksel özellikleri ile ilişkili olmadığı görülmektedir ve bağımsız olarak değerlendirilebileceği sonucu çıkarılabilir. Sonucun genellenebilmesi için örneklem sayısının arttırıldığı çalışmalarla desteklenmesi gerekmektedir. Elde edilecek veriler 1şığında uzun süreli takiplerde yaşam kalitesi parametrelerinin takibi, büyüme çağında olan çocukların gelişimlerinde görülebilecek pes planus kaynaklı problemleri en erken dönemden fark edilmesini sağlayabileceğini düşündürmektedir.

Yazarların Katkıları: Fikir/Kavram: Ş.Y., S.Ş., N.B.; Tasarım: S.Ş.; Veri Toplama ve/veya İşleme: Ş.Y.; Analiz ve/veya Yorum: Ş.Y., S.Ş., N.B.; Literatür Taraması: Ş.Y., S.Ş.; Makale Yazımı: Ş.Y., N.B.; Eleştirel İnceleme: S.Ş., N.B.

\section{KAYNAKLAR}

1. Bresnahan PJ, Juanto MA. Pediatric flatfeet-A disease entity that demands greater attention and treatment. Frontiers in Pediatrics. 2020; 8; 19.

2. El O, Akcali O, Kosay C, Kaner B, Aslan Y, Sagol E, et al. Flexible flatfoot and related factors in primary school children: a report of a screening study. Rheumatology International. 2006; 26(11): 1050-3.

3. Carr JB, Yang S, Lather LA. Pediatric pes planus: A state-of-the-art review. Pediatrics. 2016; 137(3): e20151230.

4. Şenaran H. Çocuklarda pes planus tanımı, doğal seyri ve tedavi seçenekleri. Türk Ortopedi ve Travmatoloji Birliği Derneği Dergisi. 2006; 5(1-2): 27-33.

5. Houghton KM. Review for the generalist: Evaluation of pediatric foot and ankle pain. Pediatric Rheumatology. 2008; 6: 6. 
6. Pfeiffer M, Kotz R, Ledl T, Hauser G, Sluga M. Prevalence of flat foot in preschool-aged children. Pediatrics. 2006; 118(2): 634-9.

7. Bordin D, De Giorgi G, Mazzocco G, Rigon F. Flat and cavus foot, indexes of obesity and overweight in a population of primary-school children. Minerva Pediatrica. 2001; 53(1): 7-13.

8. Staheli LT, Chew DE, Corbett M. The longitudinal arch. A survey of eight hundred and eighty-two feet in normal children and adults. The Journal of Bone and Joint Surgery. 1987; 69(3): 426-8.

9. Chen KC, Yeh CJ, Tung LC, Yang JF, Yang SF, Wang $\mathrm{CH}$. Relevant factors influencing flatfoot in preschool aged children. European Journal of Pediatrics. 2011; 170(7): 931-6.

10. Onodera AN, Sacco IC, Morioka EH, Souza PS, de Sá MR, Amadio AC. What is the best method for child longitudinal plantar arch assessment and when does arch maturation occur? Foot. 2008; 18(3): 142-9.

11. Kothari A, Stebbins J, Zavatsky AB, Theologis T. Health-related quality of life in children with flexible flatfeet: a cross-sectional study. Journal of Children's Orthopaedics. 2014; 8(6): 489-96.

12. López López D, de Los Angeles Bouza Prego M, Constenla AR, Canosa JLS, Casasnovas BA, et al. The impact of foot arch height on quality of life in 612 year olds. Colombia Medica (Cali). 2014; 45(4): 168-72.

13. Acak M, Bayer R. Pes planus olan İnönü üniversitesi öğrencilerinin fiziksel uygunluk düzeyi, yaşam kalitesi ve benlik saygılarının değerlendirilmesi. Beden Eğitimi ve Spor Bilimleri Dergisi. 2019; 21(1): 8-18.

14. Lopez-Lopez D, Vilar-Fernandez JM, Barros-Garcia G, Losa-Iglesias ME, Palomo-Lopez P, Becerro-deBengoa Vallejo R, et al. Foot arch height and quality of life in adults: a strobe observational study. International Journal of Environmental Research and Public Health. 2018; 15(7): 1555.

15. Keith R, Ashford RL, Evans A. Non-surgical interventions for paediatric pes planus. Cochrane Database of Systematic Reviews. 2010; 7(7): CD006311.

16. Van Melick N, Meddeler BM, Hoogeboom TJ, Nijhuis-van der Sanden MWG, Van Cingel REH. How to determine leg dominance: The agreement between self-reported and observed performance in healthy adults. Plos One. 2017; 12(12): e0189876.

17. Otman SA, editör. Tedavi hareketlerinde temel değerlendirme prensipleri. 7.Baskı, Ankara: Hipokrat kitabevi; 2015.

18. Kim JA, Lim OB, Yi CH. Difference in static and dynamic stability between flexible flatfeet and neutral feet. Gait Posture. 2015; 41(2): 546-50.

19. Sobel E, Levitz S, Caselli M, Brentnall Z, Tran MQ. Natural history of the rearfoot angle: preliminary values in 150 children. Foot \& Ankle International. 1999; 20(2): 119-25.

20. Katz K, Rosenthal A, Yosipovitch Z. Normal ranges of popliteal angle in children. Journal of Pediatric Orthopedics. 1992; 12(2): 229-31.

21. Nakale NT, Strydom A, Saragas NP, Ferrao PNJF. Association between plantar fasciitis and isolated gastrocnemius tightness. Foot \& Ankle International. 2018; 39(3): 271-7.

22. Redmond AC, Crane YZ, Menz HB. Normative values for the Foot Posture Index. Journal of Foot and Ankle Research. 2008; 1: 6.

23. Williams DS, McClay IS. Measurements used to characterize the foot and the medial longitudinal arch: reliability and validity. Physical Therapy. 2000; 80(9): 864-71.

24. Beighton P, Solomon L, Soskolne CL. Articular mobility in an African population. Annals of Rheumatic Diseases. 1973; 32(5): 413-7.

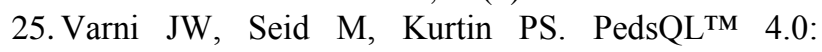
Reliability and validity of the pediatric quality of life inventory ${ }^{\mathrm{TM}}$ version 4.0 generic core scales in healthy and patient populations. Medical Care. 2001; 39(8): 800-12.

26. Kabak VY, Yakut Y, Çetin M, Düger T. Reliability and validity of the Turkish version of the pedsql 3.0 cancer module for 2-to 7-year-old and the pedsql 4.0 generic core scales for 5-to 7-year-old: The Hacettepe university experience. Turkish Journal of Hematology. 2016; 33(3): 236-43.

27. Çakın Memik N, Ağaoğlu B, Coşkun A, Karakaya I. Çocuklar için yaşam kalitesi ölçeğinin 13-18 yaş çocuk formunun geçerlik ve güvenirliği. Türk Psikiyatri Dergisi. 2007; 18(4): 353-63.

28. DiGiovanni CW, Langer P. The role of isolated gastrocnemius and combined Achilles contractures in the flatfoot. Foot and Ankle Clinics. 2007; 12(2): 36379.

29. Raymond WL, Xie KK. Association between Achilles tightness and lower extremity injury in children. HSS Journal. 2016; 12(3): 245-9.

30. Kim HW, Weinstein SL. Flatfoot in children: Differential diagnosis and management. Current Orthopaedics. 2000; 14(6): 441-7.

31. Hsieh RL, Peng HL, Lee WC. Short-term effects of customized arch support insoles on symptomatic flexible flatfoot in children: A randomized controlled trial. Medicine. 2018; 97(20): e10655.

32. Chen YC, Lou SZ, Huang CY, Su FC. Effects of foot orthoses on gait patterns of flat feet patients. Clinical Biomechanics (Bristol, Avon). 2010; 25(3): 265-70. 